\title{
Membranas biológicas homólogas preservadas em solução alcalina seguida de liofilização, glicerina a $98 \%$ e por liofilização para implantação em eqüinos
}

\author{
Homologous biological membranes persevered in alkaline solution and lyophilized, glycerin \\ $98 \%$ and by lyophilization for equines implantation
}

\author{
Valcinir Aloisio Scolla Vulcani ${ }^{{ }^{*}}$ Delphim da Graça Macorisi ${ }^{\text {II }}$ Ana Maria de Guzzi Plepis ${ }^{\text {III }}$
}

\section{RESUMO}

Objetivou-se, neste trabalho, avaliar as alterações físico-químicas proporcionadas pelo tratamento de centros tendinosos diafragmáticos homólogos em solução alcalina seguida de liofilização, para implantação na fáscia interna do músculo reto do abdome de eqüinos. As amostras foram tratadas em períodos de 24, 48, 72, 120 e 144 horas, liofilizadas e analisadas quanto à homogeneidade, flexibilidade e resistência à sutura das amostras. Posteriormente foram caracterizadas por calorimetria exploratória diferencial e microscopia eletrônica de varredura. Para a implantação nos eqüinos, foram utilizadas amostras tratadas por 72 horas seguidas de liofilização, amostras conservadas em glicerina 98\% e amostras apenas liofilizadas, que foram retiradas após uma, nove e 18 semanas para avaliar a existência de aderências. Verificou-se que a homogeneidade e a flexibilidade são diretamente proporcionais ao aumento do tempo de tratamento em solução alcalina, enquanto que a resistência é inversamente proporcional ao aumento de tempo, sendo o tratamento por 72 horas intermediário para estas características. A calorimetria exploratória diferencial mostrou que o tratamento não desnatura o colágeno presente nas amostras. Na microscopia eletrônica de varredura, observou-se que o aumento de tempo de tratamento proporciona expansão de zonas menos densas do material. Em relação à formação de aderências, as amostras apenas liofilizadas apresentaram grau máximo na formação da classificação proposta, seguida pelas amostras conservadas em glicerina 98\% com grau médio e as amostras tratadas em solução alcalina e liofilizadas, que foram classificadas em grau mínimo. Concluiu-se que o tratamento por 72 horas seria mais apropriado para implantação e que a integração tissular com a parede abdominal foi melhor em relação às amostras apenas liofilizadas e às conservadas em glicerina.

Palavras-chave: biomembranas, cirurgia reparadora, biomateriais, implante.

\begin{abstract}
The objectives in this research were to evaluate physicist-chemistries alterations in equines diaphragmatic tendineous centers implants submitted to alkaline solution and lyophilization treatment. The samples had been treated in alkaline solution for 24, 48, 72, 120 and 144 hours and lyophilized. It was analyzed the homogeneity, flexibility and resistance to the suture. After that, they had been submitted to the differential scanner calorimetry and to the scanner electronic microscopy. Samples of 72 hours in alkaline treatment, conserved in glycerin 98\% and only lyophilized were implanted in recto abdominis internal fascia of equines. They were removed one, nine and 18 weeks post-implantation to evaluate the existence of tacks. It was verified that the homogeneity and flexibility are directly proportional to the increase of time of treatment in alkaline solution while the resistance is inversely proportional to the time increase, being 72 hour treatment intermediate for these characteristics. The differential scanner calorimetry showed that the treatment do not denature the present collagen in samples. The electronic microscopy showed that the increase of treatment time provides expansion of less dense zones of the material. In relation to the formation of tacks, the samples only lyophilized had presented maximum degree in the proposal classification followed for the conserved in glycerin 98\% samples with average degree and the treated in alkaline solution and lyophilized samples had been classified in minimum degree. It was concluded that the treatment for 72 hours would be more appropriate for implantation and that the tissue integration with abdominal wall was better in relation to the samples lyophilized only and to the conserved in glycerin ones.
\end{abstract}

Key words: biomembranes, repair surgery, biomaterials, implant.

IPrograma de Pós-graduação em Cirurgia Veterinária, Faculdade de Ciências Agrárias e Veterinárias (FCAV), Universidade Estadual Paulista (UNESP). Endereço para correspondência: Av. Sallun, 777, Vila Prado, 13574-040, São Carlos, SP, Brasil. E-mail: aloisiosv@hotmail.com.*Autor para correspondência.

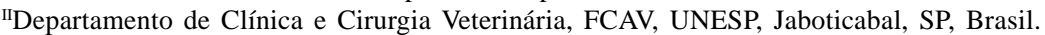

IIIDepartamento de Química e Física Molecular, Grupo de Bioquímica e Biomateriais, Instituto de Química de São Carlos (IQSC) Universidade de São Paulo (USP), São Carlos, SP, Brasil. 


\section{INTRODUÇÃO}

A necessidade de materiais para implantes é constante na rotina cirúrgica. Para isso são necessários meios de preservação dos tecidos que sejam de fácil obtenção, impeçam a decomposição e o crescimento de microorganismos, aumentem a resistência e atuem por um período necessário à condição a que estão sendo expostos (ALVARENGA, 1992).

A glicerina a $98 \%$ têm sido utilizada nas quatro últimas décadas para conservar diferentes tecidos como dura-máter (PIGOSSI et al., 1964), peritônio bovino e canino (DALECK et al., 1992), pericárdio eqüino (RANZANI et al., 1990), diafragma e bexiga caninos (MAZZANTI et al., 2000; OLIVEIRA et al., 2000) entre outros. A glicerina 98\% proporciona desidratação celular e atua contra fungos e bactérias gram-negativas e positivas, com exceção das formas esporuladas (PIGOSSI, 1967). Além da glicerina, outros meios têm sido utilizados como a solução alcoólica de tintura de timersol (ALVARENGA 1992), polivinilpirrolidona, solução hipersaturada de açúcar (NETO et al., 2000), mel não processado (AMENDOLA, 2000) e solução hipersaturada de sal (BRUN et al., 2002).

Em busca de métodos de tratamentos para obtenção de biomembranas colagênicas, GOISSIS et al. (1999) utilizaram solução alcalina com pH 13, em pericárdio bovino durante 24,48 e 72 horas. O tratamento removeu células e preservou a matriz extracelular, contribuindo para a redução da imunogenicidade. Além disso, a solução alcalina provocou a hidrólise dos grupos carboxiamidas presentes na molécula do colágeno, otimizando as propriedades piezoelétricas e estimulando o crescimento celular in vivo. Os polímeros naturais que formam a matriz extracelular interagiram com receptores específicos na superfície celular, participando ativamente dos processos que regulam a expressão fenotípica da célula e sua remodelagem (GRINNELL et al., 1999; GOISSIS et al., 1999). Obiomaterial deixou de ser apenas um arcabouço degradável para exercer sua bioatividade, ou seja, provocou uma resposta biológica específica (LANGER et al., 1990; HENCH, 1998).

Objetivou-se no presente trabalho processar biomembranas a partir de centros tendinosos diafragmáticos de eqüinos em solução alcalina por períodos de 24, 48, 72, 120 e 144 horas seguidas de liofilização e verificar as possíveis alterações macro e microscópicas proporcionadas pelo tratamento. Em seguida, buscou-se implantar cirurgicamente, na fáscia interna do músculo reto do abdome de eqüinos, amostras tratadas em solução alcalina seguida de liofilização, amostras tratadas em solução de glicerina a $98 \%$ e amostras apenas liofilizadas para serem retiradas com uma, nove e 18 semanas após a implantação a fim de verificar a formação de aderência tecidual.

\section{MATERIAL E MÉTODOS}

Foram obtidos 15 centros tendinosos diafragmáticos de eqüinos que foram a óbito por causa conhecida (com exceção dos animais que foram a óbito em razão de doenças infectocontagiosas), e de animais submetidos à eutanásia na Faculdade de Ciências Agrárias e Veterinárias de Jaboticabal.

Os centros tendinosos diafragmáticos foram lavados em solução fisiológica a $0,9 \%$, na qual permaneceram imersos por quatros horas. Cinco amostras foram submetidas a congelamento gradativo, sob temperatura de $15^{\circ} \mathrm{C}$ por 12 horas e $-15^{\circ} \mathrm{C}$ por 12 horas. Em seguida, as amostras foram pesadas e submetidas ao processo de liofilização. A cada 12 horas foram pesadas novamente as amostras, até que não houvesse diminuição da massa, indicando remoção da água presente no material.

Cinco amostras lavadas em solução fisiológica foram imersas em solução de glicerina $98 \%^{\mathrm{a}}$ (Glicerina Branca Rioquímica ${ }^{\circledR}$ ) durante 60 dias, conforme metodologia descrita por DALECK et al. (1992), (Grupo 2).

Para o grupo 3, tratou-se cinco centros tendinosos diafragmáticos em solução alcalina contendo dimetilsulfóxido e sais (cloretos e sulfatos) de sódio, potássio e cálcio. Após 24, 48, 72, 120 e 144 horas de imersão, os sais residuais foram removidos com três lavagens sucessivas com $\mathrm{H}_{3} \mathrm{BO}_{3} 3 \%$ e EDTA $3 \%$, sendo as membranas congeladas gradativamente conforme realizado com as amostras do grupo 1 (GOISSIS et al., 1999). As amostras dos grupos 1 e 3 foram esterilizadas em óxido de etileno e acondicionadas em embalagens de papel estéreis de grau cirúrgico.

\section{Avaliação macroscópica}

Homogeneidade da amostra: foram utilizadas dez amostras de cada tempo de tratamento ( $5 \times 5 \mathrm{~cm})$, dividas em quatro quadrantes. Cada quadrante foi inspecionado visualmente, com auxílio de lupa, e recebeu a classificação: r-predomínio de áreas rugosas; l-predomínio de áreas lisas; rl-equivalência entre áreas rugosas e áreas lisas; i-indefinido. Para a amostra toda, considerou-se: R-pelo menos três quadrantes com predomínio de áreas rugosas; L-pelo menos três quadrantes com predomínio de áreas lisas. RL-dois quadrantes com predomínio de áreas rugosas e dois quadrantes com predomínio de áreas lisas. I-dois ou mais quadrantes com áreas indefinidas; flexibilidade e 
viabilidade para sutura: foram utilizadas dez amostras de $(8 \mathrm{x} 4 \mathrm{~cm})$ de cada tempo de tratamento. As amostras foram hidratadas em solução fisiológica $0,9 \%$ durante 15 minutos. Fixou-se uma extremidade das amostras em prancha de isopor. Dobrando-se a amostra ao meio, somente com a utilização de pinças e porta agulhas, as extremidades foram unidas e suturadas em padrão simples contínuo com fio de náilon. Durante o procedimento, relacionou-se a dificuldade em unir as duas extremidades com a flexibilidade da amostra, classificando em 0-extremamente fácil de unir; 1-fácil de unir; 2- dificuldade média de unir; 3-difícil de unir; 4extremamente difícil de unir; resistência mecânica à sutura: foram utilizadas dez amostras de $(4 \mathrm{x} 4 \mathrm{~cm})$ de cada tempo de tratamento. As amostras foram hidratadas em solução fisiológica 0,9\% durante 15 minutos. Posteriormente uma das extremidades da amostra foi fixada em suporte de metal com presilha única em contato com toda a sua superfície. $\mathrm{Na}$ extremidade oposta, foi fixada, com fio de náilon distante 2cm da borda, uma esfera de chumbo com ponto simples. A esfera permaneceu fixada por 24 horas e sob ação da gravidade, quando classificou-se a extensão do dano causado à amostra: 0-não houve dano; 1 -corte no tecido menor que $0,5 \mathrm{~cm}$; 2 -corte no tecido maior que $0,5 \mathrm{~cm}$ e menor que $1 \mathrm{~cm}$; 3 -corte no tecido maior que $1 \mathrm{~cm}$ e menor que $2 \mathrm{~cm}$; 4 -rompimento total. Todas as amostras foram posicionadas de modo a manterem o mesmo sentido de direcionamento das fibras colagênicas e o fio de sutura aplicado na posição perpendicular às fibras; calorimetria exploratória diferencial: utilizou-se aproximadamente $10 \mathrm{mg}$ de amostras de cada tempo de tratamento submetidos a $10^{\circ} \mathrm{C} \mathrm{min}^{-1}$ sob fluxo de $\mathrm{O}_{2}$ e intervalo de temperatura de 25 a $150^{\circ} \mathrm{C}$; microscopia eletrônica de varredura: foram utilizadas cinco amostras de aproximadamente $1 \mathrm{~cm}^{2}$ de cada tempo de tratamento, as quais foram recobertas com uma camada de ouro de 20nm e aplicouse feixe de elétrons entre 10 e $20 \mathrm{keV}$. Observou-se, em aumentos de 100 e 500 vezes, toda a extensão das amostras.

Para a implantação cirúrgica, foram utilizados seis eqüinos adultos saudáveis e o seguinte protocolo anestésico: tranqüilização com acepromazina na dose de $0,10 \mathrm{mg} \mathrm{kg}^{-1}$, intravenoso; indução anestésica com eter gliceril guaicol na dose de $50 \mathrm{mg} \mathrm{kg}^{-1}$ associado ao

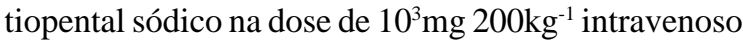
e manutenção da anestesia com halotano, por via inalatória, vaporizado em oxigênio a 100\% em circuito semifechado.

Após tricotomia e anti-sepsia, foram feitas três incisões paramedianas, divulsão do subcutâneo e exposição da bainha interna do músculo reto do abdome para retirada de três fragmentos $(2 \mathrm{x} 3 \mathrm{~cm})$. Amostras $(2 \times 3 \mathrm{~cm})$ de cada grupo foram fixadas na bainha interna com sutura padrão contínuo simples com fio poliglactina 910 n.0. A bainha externa foi suturada em padrão contínuo simples e a pele suturada em padrão colchoeiro horizontal contínuo, ambas com fio monofilamentar de poliamida n.2-0. No período póscirúrgico imediato, os animais receberam penicilina procaína (Agrovet. Novartis ${ }^{\circledR}$ ) na dose $22000 \mathrm{UI} \mathrm{kg}^{-1}$ por via intramuscular a cada 24 horas, durante três dias consecutivos.

Em cada animal foram feitos três blocos cirúrgicos constituídos por amostras dos três grupos, em posição alternada, de forma a minimizar o erro experimental, totalizando nove amostras por animal, conforme ilustrado na figura 1. Alternou-se também a posição de cada bloco nos seis animais. As amostras do grupo 2 foram submetidas à solução de antibiótico durante 15 minutos, em seguida, elas foram lavadas com solução fisiológica 0,9\%, antes da implantação.

Nas primeiras 12 horas pós-cirúrgicas, os animais permaneceram em baia e posteriormente em piquetes, recebendo feno, ração para eqüinos e água ad libitum. Realizou-se diariamente limpeza da ferida cirúrgica, aplicação tintura de iodo a $2 \%$ e aplicação de repelente ao redor da ferida, durante oito dias consecutivos, quando foram removidas as suturas de pele.

Durante a retirada dos tecidos na primeira, nona e décima oitava semana após a implantação das amostras, avaliou-se a ocorrência de aderência tecidual sobre o implante, segundo a classificação: ausência de aderências (0); aderência mínima (+) - liberação da amostra dos tecidos adjacentes por dissecação romba suave; aderência moderada (++) - liberação da amostra dos tecidos adjacentes por dissecação romba agressiva; aderência máxima (+++) - impossibilidade de liberação por dissecação romba (SUZIGAN et al. 2001).

Após as cirurgias de implantação e retirada das amostras, os animais foram avaliados clinicamente considerando-se freqüências cardíaca e respiratória, tempo de preenchimento capilar, temperatura retal, avaliação de mucosas e condições de cicatrização da ferida cirúrgica.

\section{RESULTADOS}

Homogeneidade das amostras: para o tratamento durante 24 horas, verificou-se que $40 \%$ das amostras foram classificadas em I-um ou mais quadrantes com áreas indefinidas, 30\% das amostras foram classificadas em RL-dois quadrantes com 


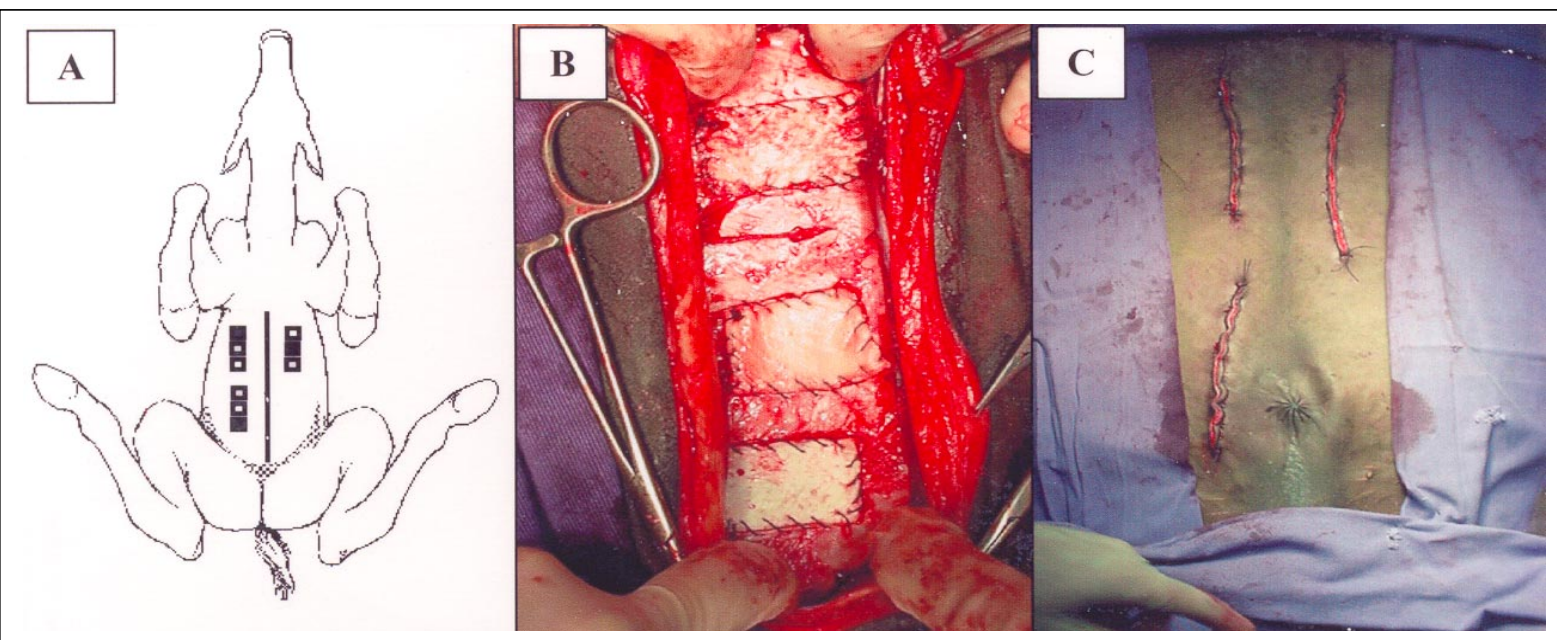

Figura 1 - Em (A), representação esquemática dos blocos de implantes na bainha interna do músculo reto do abdome dos eqüinos. Quadrado em preto representando amostras tratadas em solução alcalina seguida de liofilização; Quadrados cinza representando amostras tratadas em solução de glicerina a 98\% e quadrados brancos representando amostras apenas liofilizadas. Em (B), aspecto das amostras recém-implantadas na bainha interna do músculo reto do abdome. As amostras foram colocadas em uma distância mínima de $4 \mathrm{~cm}$ em relação às adjacentes do mesmo bloco de implantes. Em (C), fotografia digital do abdômen de um eqüino após o procedimento cirúrgico de implantação e sutura de pele.

predomínio de áreas rugosas e dois quadrantes com predomínio de áreas lisas e 20\% foram classificadas em R-pelo menos três quadrantes com predomínio de áreas rugosas. Em relação às amostras do grupo tratado durante 48 horas, 30\% foram classificadas em I, 30\% classificadas em RL, 20\% em R e 20\% em L-pelo menos três quadrantes com predomínio de áreas lisas. No tempo de tratamento por 72 horas obteve-se $80 \%$ em L e $20 \%$ em RL. Nas amostras tratadas durante 120 e 144 horas, $100 \%$ das amostras foram classificadas em L.

Flexibilidade e viabilidade para sutura: as amostras tratadas em 24 e 48 horas foram classificadas em $90 \%$ e 80\% na classificação 3-difícil de unir e 10\% e 20\% na classificação 2-dificuldade média de unir, respectivamente. Nas amostras tratadas por 72 horas, $90 \%$ foram classificadas em 1-fácil de unir e 10\% em 2dificuldade média de unir. Nas amostras tratadas em 120 e 144 horas, $100 \%$ foram classificas em classificação 0-extremamente fácil de unir.

Resistência mecânica à sutura: no tratamento por 24 e 48 horas, $90 \%$ e $80 \%$ das amostras, respectivamente, foram classificadas em 0-não houve dano e 10\% e $20 \%$ foram classificadas em 1 -corte no tecido menor que $0,5 \mathrm{~cm}$. Para o tratamento de 72 horas, $60 \%$ das amostras foi classificada em 0, 30\% em 1 e 10\% em 2-corte no tecido maior que $0,5 \mathrm{~cm}$ e menor que $1 \mathrm{~cm}$. As amostras tratadas em 120 horas apresentaram 70\% das amostras em classificação 3 -corte no tecido maior que $1 \mathrm{~cm}$ e menor que $2 \mathrm{~cm}, 20 \%$ em 2 -corte no tecido maior que $0,5 \mathrm{~cm}$ e menor que $1 \mathrm{~cm}$ e $10 \%$ em 4-rompimento total. As amostras tratadas durante 144 horas apresentaram 80\% em 3 e 20\% em 4.
Análise térmica: a análise das curvas de calorimetria exploratória diferencial permitiu verificar que não houve desvio na linha de base, comprovando que o colágeno não foi desnaturado durante o tratamento alcalino, mantendo suas características naturais.

Microscopia eletrônica de varredura: observando as fotomicrografias das amostras conservadas em diferentes tempos em solução alcalina, verificou-se aspecto irregular, com zonas bastante densas, e outras menos densas, mostrando a presença de arranjos de fibras randomicamente dispostos, mas compactos em alguns pontos. No entanto, notou-se que o aumento do tempo de conservação das amostras proporciona expansão de zonas menos densas do material (Figura 2)

Avaliação cirúrgica: todas as amostras do grupo 1, durante a retirada, foram classificadas no grau máximo de dificuldade, na primeira e nona semanas de permanência dos implantes. Já as amostras do grupo 2, em sua grande maioria ficaram na classificação de aderência moderada na primeira e nona semanas, sendo que nesta última as amostras ficaram no grau máximo de dificuldade de retirada em dois animais. As amostras do grupo 3 ficaram na classificação mínima de dificuldade de retirada durante a primeira semana e nona semanas e, em dois animais, apresentaram classificação moderada de dificuldade de retirada.

As amostras retiradas após 18 semanas foram somente do tecido cicatricial, não sendo possível visibilizar a existência de aderências, em virtude das 

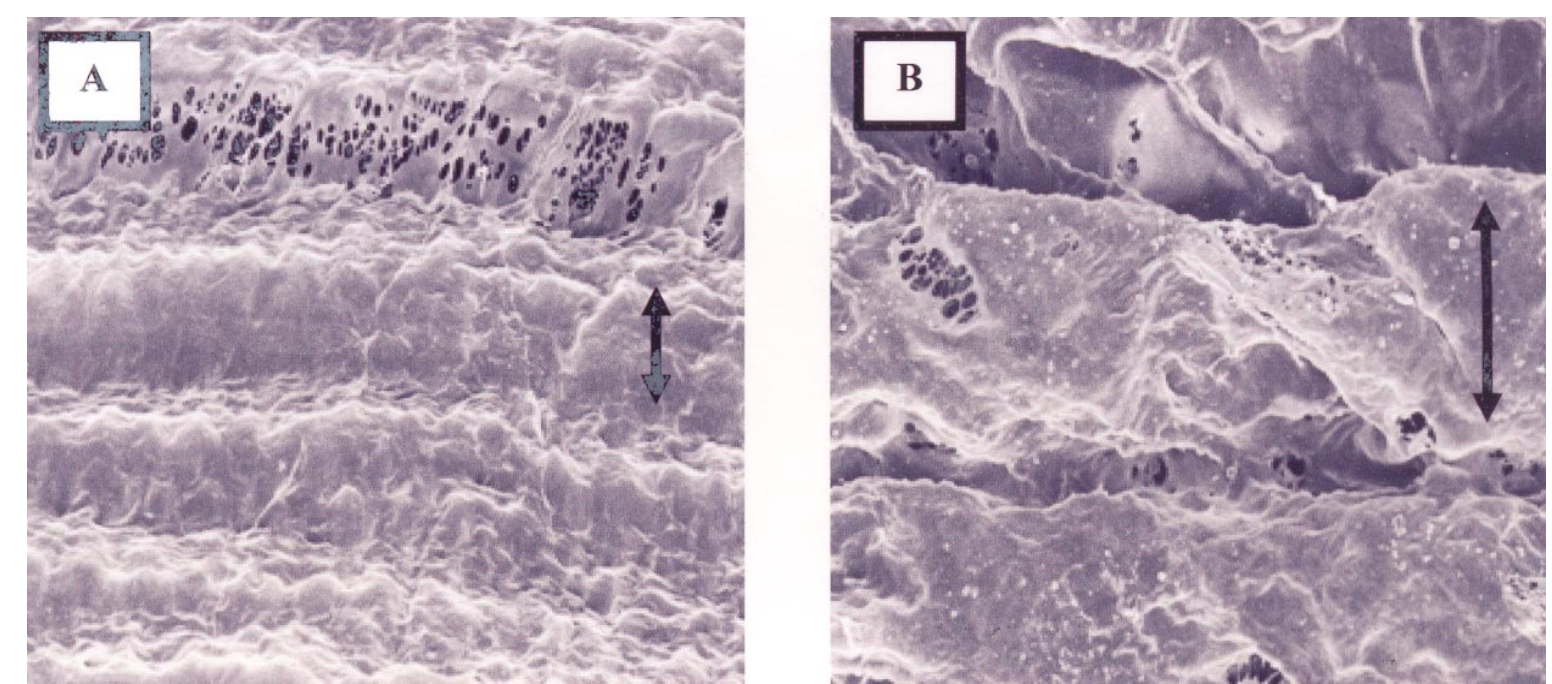

Figura 2 - Fotomicrografias das amostras submetidas à conservação em solução alcalina por 72 horas (A) e 144 horas (B). Observase expansão das zonas menos densas do material em virtude do aumento do tempo de conservação em solução alcalina (vetores de sentido duplo). Aumento de 500 vezes.

amostras terem sido completamente degradadas, dificultando a análise. Em relação aos parâmetros clínicos dos animais receptores, não foi notada qualquer alteração digna de nota.

\section{DISCUSSÃO}

O aumento da flexibilidade e da homogeneidade e a diminuição da resistência das amostras em função do tempo de tratamento em solução alcalina foi compatível com os resultados obtidos por microscopia eletrônica de varredura, pois a expansão das zonas menos densas foi diretamente proporcional ao tempo de imersão das amostras em solução alcalina. $\mathrm{O}$ aumento das zonas menos densas de um biomaterial altera as características de resistência mecânica em virtude da existência de menor massa e conseqüentemente menor interação molecular para resistir aos diversos estresses a que um implante é submetido (HENCH et al., 2006).

No entanto, essas alterações se deram pela modificação da disposição das fibras de colágeno e não pela modificação da molécula de tropocolágeno, conforme evidenciado pela análise térmica por calorimetria exploratória diferencial, cujas curvas mostraram que não houve desnaturação protéica do colágeno durante o tratamento alcalino (GOISSIS et al., 1999; BET, 2000).

Das características observadas, verificouse que o tempo de tratamento por 72 horas foi o que proporcionou flexibilidade às amostras, facilitando a manipulação pelo cirurgião, porém, sem perder resistência considerável em relação a tempos superiores.
Em relação à remoção cirúrgica dos tecidos, houve maior facilidade na remoção das amostras tratadas em solução alcalina em relação às preservadas em glicerina e apenas liofilizadas, provavelmente, devido à capacidade do tratamento em remover resíduos teciduais e alterar grupos carboxiamidas das moléculas de colágeno, que são responsáveis por ocasionar respostas nos organismos hospedeiros (GOISSIS et al., 1999; DE PAULA et al., 2002), inclusive na formação de fibrose (PEREIRA et al., 2000) .

\section{CONCLUSÕES}

Concluiu-se que o tempo mais adequado para a conservação das membranas biológicas em solução alcalina seguida de liofilização é de 72 horas e que esse método proporciona melhor integração tissular com os tecidos da parede abdominal de eqüinos, em relação ao método de conservação de biomembranas em glicerina $98 \%$ e às membranas apenas liofilizadas.

\section{AGRADECIMENTOS}

À Fundação de Amparo à Pesquisa do Estado de São Paulo (Fapesp), pelo suporte financeiro. À Coordenação de Aperfeiçoamento de Pessoal de Nível Superior (Capes), pela bolsa concedida. Ao Laboratório de Bioquímica e Biomateriais (IQSC - USP). À empresa Oxetil ${ }^{\circledR}$.

\section{COMISSÃO DE ÉTICA E BIOSSEGURANÇA}

Aprovado pela comissão de ética e bem-estar animal, no 005024-05 - FCAVJ.

Ciência Rural, v.38, n.5, ago, 2008. 


\section{REFERÊNCIAS}

ALVARENGA, J. Possibilidades e limitações da utilização de membranas biológicas preservadas em cirurgia. In: DALECK, C.R. Tópicos em cirurgia de cães e gatos. Jaboticabal: FUNEP-UNESP, 1992. p.33-42.

AMENDOLA, G.F. et al. Traqueoplastia em coelhos com centro frênico canino conservado em mel. Ciência Animal Brasileira. v.1, suplemento, p.111, 2000.

BET, M.R. Colágeno aniônico: propriedades físicoquímicas, estruturais e comportamento biológico. 2000. 107f. Tese (Doutorado em Química Analítica) - Instituto de Química de São Carlos, Universidade de São Paulo.

BRUN, M.V. et al. Solução hipersaturada de sal como conservante de pericárdio canino utilizado na reparação do músculo reto abdominal de ratos Wistar. Ciência Rural, v.32, n.6, p.1019-1025, 2002.

DE PAULA, M. et al. Compósitos de colágeno aniônico:ramsana como géis injetáveis para correções plástica: preparação, caracterização e propriedades reológicas. Revista Brasileira de Engenharia Biomédica, v.18, n.1, p.7-16, 2002.

DALECK, C.R. et al. Reparação de hérnia perineal em cães com peritônio de bovino conservado em glicerina. Ciência Rural, v.22, n.2, p.179-183, 1992.

GRINNELL, F. et al. Differences in the regulation of fibroblast contraction of floating versus stressed collagen matrices. Journal of Biological Chemistry v.274, p.918-923, 1999.

GOISSIS, G. et al. Surface tension controll of collagen biomaterials by the selective hydrolysis of internal carboxyamides of the protein matrix. Revista Brasileira de Engenharia Biomédica, v.15, p.55-61, 1999.

HENCH, L.L. Biomaterials: a forecast for the future. Biomaterials, v.19, n.4/5, p.419-423, 1998.

HENCH, L.L. et al. Biocompatibilidade, bioatividade e engenharia de tecidos. In: ORÉFICE, R. L. et al. Biomateriais: fundamentos e aplicações. Rio de Janeiro: Cultura Médica, 2006. Cap.16. p.479-506.

LANGER, R. et al. Future directions in biomaterials. Biomaterials, Guidford, v.11, n.9, p.738-745, 1990.

MAZZANTI, A. et al. Reparação da traquéia de cão com segmento muscular homólogo de diafragma conservado em glicerina a 98\%. Ciência Rural, v.30, n.6, p.1011-1016, 2000.

NETO, J.M.C. et al. Ação antimicrobiana da glicerina a $98 \%$ e da solução aquosa de iodo povidona. In: CONGRESSO BRASILEIRO DE CIRURGIA E ANESTESIOLOGIA VETERINÁRIA, 4., 2000, Goiânia, GO. Ciência Animal Brasileira... Goiânia: CBCA, 2000. p.97.

OLIVEIRA, L.O. et al. Implante homógeno de bexiga conservada em glicerina a $98 \%$ para reparo da bexiga de cães. Arquivos da Faculdade de Veterinária UFRGS, v.27, n.1, p.90-102, 2000.

PEREIRA, F.E.L. et al. Inflamações. In: BRASILEIRO FILHO, G. Bogliolo patologia. 6.ed. Rio de Janeiro: Guanabara Koogan, 2000. Cap.7, p.112-148.

PIGOSSI, N. A glicerina na conservação de dura-mater estudo experimental. 1967. 36f. Tese (Livre docência) Faculdade de Medicina de São Paulo, Universidade de São Paulo.

RAISER, A.G. et al. Homoimplante ortotópico de tendão calcâneo em cães. Conservação assepsia e implantação. Ciência Rural, v.31, n.1, p.89-94, 2001.

RANZANI, J.J.T. et al. Implante de pericárdio de eqüino em glicerina em solução de continuidade do diafragma de cão. Brazilian of Journal Veterinary Research and Animal Science, v.27, n.1, p.65-73, 1990.

SUZIGAN, S. et al. Anomalous metaplastic ossification of anionic collagen coated plypropilele mesh after implantation in the abdominal wall. In: CONGRESO VIRTUAL HISPANO AMERICANO DE ANATOMÍA PATOLÓGICA, 4., 2001. Acesso 01 jul. 2005. Online. Disponível em: http:// conganat.uniovi.es/posters/120/texto.htm:1- 